\title{
Development of energy-efficient heat-insulating foam
}

\author{
Oleg Selivanov ${ }^{*}$, Vladimir Chukhlanov, and Marina Ilina $^{1}$ \\ ${ }^{1}$ Vladimir State University named after A.G. and N.G. Stoletovs Vladimir, 600000, Russia
}

\begin{abstract}
The paper presents the research results dealing with the development of energy-efficient thermal insulation material based on the binder of $10 \%$ polycarbosilane solution in xylene, filled with various hollow microspheres and fibrous filler from quartz fibers. According to the research results the best effect was demonstrated by the samples of thermal insulation material, containing hollow carbon microspheres as filler. When the binder contains $10 \%$ of polycarbosilane solution in xylene- $15-70 \%$ wt., hollow carbon microspheres $12-65 \%$ wt. and quartz fibers $8-43 \%$ wt., the resulting foam possesses reduced density, low thermal conductivity and good strength characteristics. It allowed this material to be recommended for the use as energy-efficient heat-resistant insulation in various industries, including power and aircraft engineering.
\end{abstract}

\section{Introduction}

Nowadays composite materials based on polymer binders are widely used in various industries [1-4]. Foams containing polymer binder filled with hollow microspheres is one of the polymer composite materials type. Depending on the required technical and operational characteristics of the particular foam and the desired field of application, various polymers and reactive oligomers have been used as a binder [5-7]. Hollow microspheres make foams possess such characteristics as low thermal conductivity and low density, which allow them to be used as thermal insulation materials. Besides powdered and fibrous fillers, as well as pigments, heat stabilizers, various target additives can be introduced into the polymer composite materials, including foams, to enhance their strength and adhesive properties. In some cases, for example, at high temperature operating conditions, foams must by significantly heat resistant. Polyorganosiloxane binders are commonly used to produce heat-resistant foams. The application of such binders is associated with high energy of oxygen-silicon bond in the main chain of the polymer macromolecule [5]. However, the upper temperature limit where polyorganosiloxane binder based foams retain their performance does not exceed $250 \mathrm{oC}$. For example, foam based on siloxane copolymer, titanium potassium fibers, quartz microspheres, boric acid starts losing its mechanical strength at the temperature of $300^{\circ} \mathrm{C}$. Similarly, the foam based on polymethylphenylsiloxane resin, hollow quartz microspheres and amine hardener loses its performance characteristics at the temperature above $300 \mathrm{oC}$. It is explained by the fact that

\footnotetext{
*Corresponding author: selivanov6003@mail.ru
} 
at higher temperatures, in addition to thermal oxidation destruction, thermal destruction processes occur, causing irreversible deformation of foams and loss of their operational properties. The research objective is to develop energy-efficient heat-insulating foam based on organosilicon binder, using hollow microspheres and fibrous filler, characterized by low thermal conductivity and low density, in comparison with the other known foams, and has an upper limit of thermal resistance of 700o, which will significantly expand the scope of polyorganosiloxane foams application.

\section{Materials and methods}

For the development of heat-resistant heat-insulating foam $10 \%$ solution of polycarbosilane in xylene was used as a binder. To prepare the organosilicon binder in the form of solution in xylene, powdered polycarbosilane with the molecular weight of 25003500 was used with the following structural formula (Fig.1):

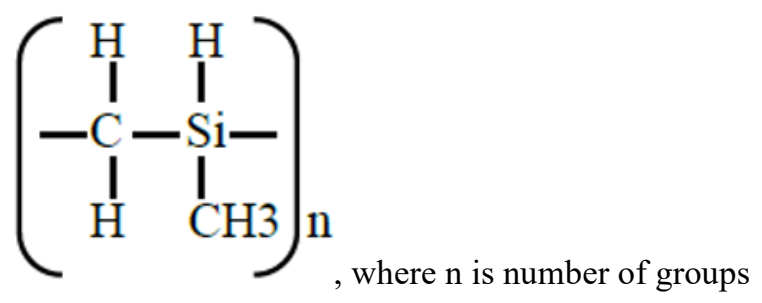

Fig.1. Structural formula of organosilicon binder of polycarbosilane

It should be noted that depending on the polycarbosilane production method, its structure is characterized by relatively small, but highly branched linear-cyclic molecules, possessing a large number of cross-links and active side links. Anyway, polycarbosilane molecules mainly contain Si-C bonds, providing the connection of silicon atoms with the organic group and having sufficient strength (binding energy $313 \mathrm{~kJ} / \mathrm{mole}$ ) and, as a consequence, giving polymer composite, based on polycarbosilane, strength and heat resistance. Partial thermal separation of hydrocarbon groups causes cross-linking between molecules, but the polymer chain itself is thermally stable and no deformation occurs.

Hollow ceramic and hollow carbon microspheres were used as hollow microspheres for the development of thermal insulation foam. Hollow ceramic microspheres are produced by the flotation treatment of flue emissions from thermal power plants operating on solid fuel. Hollow ceramic microspheres from the coal-fired thermal power plants were used in the research. Ceramic microspheres are hollow, almost perfectly shaped silicate microspheres having smooth surface. Their diameter is from 10 to 600 micrometers, an average of about 100 microns. The shells are solid nonporous, shell thickness is from 2 to 10 microns. The inner cavity of the particles is filled with nitrogen and carbon dioxide $\mathrm{CO}_{2}$. The used hollow ceramic microspheres were of the following elemental composition: $57 \% \mathrm{SiO}_{2}, 28 \%$ $\mathrm{Al}_{2} \mathrm{O}_{3}$, the rest include oxides $\mathrm{CaO}, \mathrm{MgO}, \mathrm{Na}_{2} \mathrm{O}, \mathrm{Fe}_{2} \mathrm{O}_{3}$.

Hollow carbon microspheres were obtained by phenol formaldehyde hollow microspheres pyrolysis in argon medium at the temperature of $1200 \mathrm{oC}$ during 4 hours. The resulting microspheres ranged from 20 to 100 microns in size.

Quartz fibers $\left(\mathrm{SiO}_{2}-99.9 \%\right)$ with the length of 50-500 microns and diameter of $0.7-$ 2.5 microns were used as fibrous filler.

Thermal conductivity coefficient was determined in compliance with GOST 23630-79 using the device IT- $\lambda-400$. Compressive strength was determined in compliance with GOST 8462-85. The apparent density of foam samples was determined in compliance with GOST 409-2017. 
The composition for the foam was prepared by mixing the components in a mixer. The mixer was filled with $10 \%$ wt. of polycarbosilane solution in xylene, further quartz fibers were introduced, and after mixing hollow ceramic or hollow carbon microspheres were added. The mixture was stirred at $100-130^{\circ} \mathrm{C}$ to remove the solvent, afterwards the samples were formed and placed into the furnace for heating at the speed of $100^{\circ} \mathrm{C} / \mathrm{h}$ in the nitrogen atmosphere up to $1000^{\circ} \mathrm{C}$. Thus, two types of foam samples were produced: containing hollow ceramic microspheres and hollow carbon microspheres.

\section{Results and discussion}

At the first stage of the research the compositions for producing foam samples according to the above technology were developed. Totally 10 samples were produced: 5 foam samples with hollow carbon microspheres and 5 foam samples with hollow ceramic microspheres. Compositions for producing foam samples are presented in table 1.

Table 1. Compositions content for producing foam samples.

\begin{tabular}{|c|c|c|c|c|}
\hline \multirow{2}{*}{$\begin{array}{c}\text { Sample } \\
\text { № }\end{array}$} & \multicolumn{4}{|c|}{ Compositions content, wt. \% } \\
\hline & $\begin{array}{c}10 \% \text { solution of } \\
\text { polycarbosilane in } \\
\text { xylene }\end{array}$ & $\begin{array}{c}\text { Hollow carbon } \\
\text { microspheres }\end{array}$ & $\begin{array}{l}\text { Hollow ceramic } \\
\text { microspheres }\end{array}$ & Quartz fibers \\
\hline 1 & 15.0 & 65.0 & - & 20.0 \\
\hline 2 & 45.0 & 12.0 & - & 43.0 \\
\hline 3 & 70.0 & 22.0 & - & $8, .0$ \\
\hline 4 & 5 & 75,0 & - & 20.0 \\
\hline 5 & 85 & 12.0 & - & 3.0 \\
\hline 6 & 15.0 & - & 65.0 & 20.0 \\
\hline 7 & 45.0 & - & 12.0 & 43.0 \\
\hline 8 & 70.0 & - & 22.0 & 8.0 \\
\hline 9 & 5 & - & 75.0 & 20.0 \\
\hline 10 & 85 & - & 12.0 & 3.0 \\
\hline
\end{tabular}

In all cases, quartz fibers were used as a reinforcing additive for producing foam samples. Quartz fibers are known to be commonly used when significant thermal resistance and strength of the resulting products is required, so their introduction into the foam composition should provide an increase of these important parameters.

At the second stage, the properties of the produced foam samples were studied. The basic properties of the developed thermal insulation foams are presented in table 2 . We have chosen hollow ceramic microspheres and hollow carbon microspheres for the formulation of thermal insulation foam primarily due to their high strength, low bulk density and low thermal conductivity. It should be noted that hollow carbon microspheres have already found their application in the development of composite materials based on polymer binders, in the development of spheroplastics, syntactic closed-cell foam plastic of low density and thermal conductivity. 
Table 2. Properties of thermal insulation foam samples.

\begin{tabular}{|l|l|l|l|l|l|}
\hline \multirow{2}{*}{$№$} & \multicolumn{5}{|c|}{ Properties of thermal insulation foam } \\
\cline { 2 - 6 } & $\begin{array}{c}\text { Apparent } \\
\text { density } \\
\mathrm{kg} / \mathrm{m}^{3}\end{array}$ & $\begin{array}{c}\text { Thermal } \\
\text { conductivity at } \\
25^{\circ} \mathrm{C}, \mathrm{W} / \mathrm{MK}\end{array}$ & $\begin{array}{l}\text { Tensile strength } \\
\text { at compression, } \\
\mathrm{MPa}\end{array}$ & $\begin{array}{c}\text { Compressive } \\
\text { strength limit } \\
\text { after 10h at } 700^{\circ} \mathrm{C} \\
\text { in the air, MPa }\end{array}$ & $\begin{array}{l}\text { Visual } \\
\text { control }\end{array}$ \\
\hline 1 & 242 & 0.12 & 4.9 & 4.2 & - \\
\hline 2 & 336 & 0.18 & 5.1 & 5.8 & - \\
\hline 3 & 395 & 0.23 & 6.1 & 7.3 & - \\
\hline 4 & - & - & - & - & $\begin{array}{l}\text { Deform } \\
\text { ation }\end{array}$ \\
\hline 5 & - & - & - & - & $\begin{array}{l}\text { Deform } \\
\text { ation }\end{array}$ \\
\hline 6 & 399 & 0.18 & 5.1 & 4.7 & - \\
\hline 7 & 482 & 0.23 & 5.7 & 6.4 & - \\
\hline 8 & 565 & 0.26 & 7.5 & 7.8 & - \\
\hline 9 & - & - & - & - & $\begin{array}{l}\text { Deform } \\
\text { ation }\end{array}$ \\
\hline 10 & - & - & - & - & $\begin{array}{l}\text { Deform } \\
\text { ation }\end{array}$ \\
\hline
\end{tabular}

The table demonstrates that the introduction of hollow carbon microspheres into the composition does not reduce strength characteristics of the developed thermal insulation foam since carbon microspheres surface is rough, compared to the surface of ceramic microspheres. Surface roughness enhances intermolecular adhesion forces between the carbon microspheres surface and the binder. After 10 hours exposure at $700 \mathrm{oC}$ in the air, the compressive strength of the resulting foam using hollow carbon microspheres is 4.2-7.3 $\mathrm{MPa}$, which is practically comparable to the performance of foam samples containing hollow ceramic microspheres filler.

Simultaneously, hollow carbon microspheres have lower weight and lower coefficient of thermal conductivity than hollow ceramic microspheres, so their introduction into the composition improves thermal insulation properties of the resulting foam and reduces its specific weight. Samples of thermal insulation material with hollow carbon microspheres filler have significantly lower apparent density and thermal conductivity, compared to the samples of hollow ceramic microspheres foam.

Table 2 proves that organosilicon binder introduction into the composition in the amount of up to $5 \% \mathrm{wt}$. and more than $87 \% \mathrm{wt}$. causes deformation of the produced foam samples, so the optimal amount of $10 \%$ polycarbosilane solution in xylene is $15-70 \% \mathrm{wt}$.

Comparative characteristics of the known foam and the developed organosilicon foam, produced on the basis of composition containing $15-70 \% \mathrm{wt}$. of polycarbosilane solution in xylene, $12-65 \%$ wt. hollow carbon microspheres and $8-43 \%$ wt. quartz fibers, are presented in table 3 . 
Table 3. Technical characteristics of known and developed foam.

\begin{tabular}{|l|l|c|c|}
\hline № & \multicolumn{1}{|c|}{ Specification } & \multicolumn{2}{c|}{ Value } \\
\hline \multicolumn{1}{|c|}{ Foam } & Known & Developed \\
\hline 1. & $\begin{array}{l}\text { Thermal conductivity, at } 250^{\circ} \mathrm{C}, \\
\text { W/MK }\end{array}$ & 0.26 & $0.12-0.23$ \\
\hline 2. & Apparent density, $\mathrm{kg} / \mathrm{m}^{3}$ & 686 & $242-395$ \\
\hline 2. & Tensile strength at compression, $\mathrm{MPa}$ & 4.6 & $4.9-6.1$ \\
\hline 3. & $\begin{array}{l}\text { The limit of compressive strength } \\
\text { after } 10 \mathrm{~h} \text { at } 700^{\circ} \mathrm{C} \text { in the air, } \mathrm{MPa}\end{array}$ & $\begin{array}{c}\text { Sample } \\
\text { destruction }\end{array}$ \\
\hline
\end{tabular}

\section{Conclusions}

Thus, the research resulted in the development of the foam based on polycarbosilane, hollow carbon microspheres and quartz fibers, which is superior to the previously known polyorganosiloxane foams regarding heat resistance and strength. It has low thermal conductivity and density, thus it can be recommended for the application as a hightemperature energy-efficient thermal insulation material, expanding the scope of its application, including such high-tech industries as power and aircraft engineering.

\section{References}

1. Shakhova V., Vitkalova I., Torlova A., Pikalov E., Selivanov O. MATEC Web of Conferences. 2018. Vol. 193, 03032.

2. Vitkalova, I., Torlova, A., Pikalov, E., Selivanov, O. Advances in Intelligent Systems and Computing. 2019. Vol. 983. pp. 786-794.

3. Vitkalova I., Torlova A., Pikalov E., Selivanov O. MATEC Web of Conferences. 2018. Vol. 193, 03035.

4. Chukhlanov V.Y., Selivanov O.G., Trifonova T.A., Ilina M.E., Chukhlanova N.V. International Journal of Applied Engineering. 2017.Vol.12. №7. P.1194-1199 .

5. Perovskaya K., Petrina D., Pikalov E., Selivanov O. E3S Web of Conferences. 2018. Vol. 91, 04007.

6. Chukhlanov V.Y., Selivanov O.G. Glues. Sealants. Technologies. 2015. 3. pp. 6-10.

7. Vitkalova, I., Torlova, A., Pikalov, E., Selivanov, O. Advances in Intelligent Systems and Computing. 2019. Vol. 983. pp. 778-785. 